\title{
Study of Laser Cutting and Marking on The Filt with the Help of a $\mathrm{CO}_{2}$-Laser
}

\author{
Lazov Lyubomir \\ Rezekne Academy of Technologies, \\ Faculty of Engineering) \\ Address: Atbrivosanas aleja 115,) \\ Rezekne, LV-4601, Latvia \\ 1lazov@abv.bg
}

\author{
Peneva Madlen Nikolaeva \\ National Military University , Vasil \\ Levski“, Veliko Tarnovo, Bulgaria \\ Veliko Tarnovo, Bulgaria \\ merianp98@gmail.com
}

\author{
Dolchinkov Nikolay Todorov \\ National Military University , Vasil \\ Levski “, Veliko Tarnovo, Bulgaria \\ National Research University "Moscow \\ Power Engineering Institute", Moscow, \\ Russia \\ Veliko Tarnovo, Bulgaria \\ n_dolchinkov@abv.bg \\ Bojhanova Denitsa Angelova \\ National Military University ,, Vasil \\ Levski“, Veliko Tarnovo, Bulgaria \\ Veliko Tarnovo, Bulgaria \\ denica_a_b@abv.bg
}

\author{
Ivanov Jordan Shterev \\ National Military University , Vasil \\ Levski “, Veliko Tarnovo, Bulgaria \\ Veliko Tarnovo, Bulgaria \\ jshterev@abv.bg
}

\begin{abstract}
Describe the parameters influencing the depth of the laser marking of textile products. Experimental results are presented to determine the quality of cuts on felt surfaces of different colors at specific parameters - power and speed. Approximately 100 extras were made on two materials with a change in laser power and speed. As a result, the optimal results for cutting and marking a felt are shown.
\end{abstract}

Keywords - cutting, filt, laser, marking, research.

\section{INTRODUCTION}

The felt is a soft fabric which is made not by weaving but by pressing under steam or hot water and felting of animal fibers. A $100 \%$ synthetic fiber felt felt felted as well as felt from a combination of animal, vegetable or artificial fibers.

Felting is probably the oldest form of fabrication known to mankind before weaving and knitting.

Today traditional felting is still practiced by the nomadic tribes in Asia, producing mats, tents and clothing. Because of its qualities such as strength, heat and sound insulation, the felt is used in the textile industry, but also in machine-building, woodworking and others.

Most commonly this material is used for the production of articles, useful for households, for example, sealing in various branches of industry - machine-building, paperpulp industry, also as an insulating material, for polishing, etc. Often, the felt also serves as an upholstery on different surfaces. However, because it is thick cutting intricate patterns and structures into felt is difficult to do by hand. Precise cutting is usually done by means of an industrial mashine cutter. Using a laser to cut felt is great choose.

The laser has moved in 58 years from "a solution looking for a problem" to a key technology that contributes to major sectors of the world economy. Laser devices are the core technology in instruments performing vital functions in many industries including transportation, healthcare, and telecommunications [4].

Laser marking and laser cutting technology is now widely associated with textiles and in particular with felt $[3,5,13,15]$. In this paper we present some experimental results from this area.

After researches were made, we found out that the main factor for the difference in laser cutting on white and red felt is the difference in the color of the material. Another factor is its thickness - of the white felt it is 0.63 $\mathrm{mm}$. and for the red felt $-0.67 \mathrm{~mm}$.

There are different kind of lasers which are:

-depending on the spectral field: $\mathrm{CO}_{2}$ laser, $\mathrm{Nd}$ :YAG, ruby laser, excimer laser

-depending on the active middle: solid-state, gas, liquid and semiconductor

-depending on the power: low-powered (under 100 $\mathrm{W})$, middle-powered $(100-500 \mathrm{~W})$, powered $(1 \mathrm{~kW}-100$ $\mathrm{kW}$ ), over-powered (over $100 \mathrm{~kW}$ ).

-depending on the possibility to change the frequency: with fixed frequency; with possibility to change the frequency [17].

\section{EXPERIMENTAL SETTING}

The possibility of marking and engraving on a standard felt in two colors - red and white with $\mathrm{CO}_{2}$ laser was studied. For this purpose, an experimental methodology has been developed, which concludes in the following:

a matrix of 9 squares with $1: 1 \mathrm{~cm}(10 \times 10 \mathrm{~mm})$ is created. The speed and power range in the range of $100 ? 50$ $\mathrm{mm} / \mathrm{s}$ and 2, 10 and $26 \mathrm{~W}$. The matrix scheme is shown in the figures:

Gas laser CHANXAN CW 1325 CO2 active, 1-150 watts power, 1-400 $\mathrm{mm} / \mathrm{s}$, laser beam wavelength 10.6 $\mathrm{mm}$, maximum marking area: 2500 x $1300 \mathrm{~mm}$, maximum

Print ISSN 1691-5402

Online ISSN 2256-070X

http://dx.doi.org/10.17770/etr2019vol3.4202

(C) 2019 Lazov Lyubomir, Dolchinkov Nikolay Todorov, Ivanov Jordan Shterev, Peneva Madlen Nikolaeva, Bojhanova Denitsa Angelova.

Published by Rezekne Academy of Technologies.

This is an open access article under the Creative Commons Attribution 4.0 International License. 
laser size focal spot is $100 \mathrm{~mm}$ and water cooling system was used - Fig 1 [10].

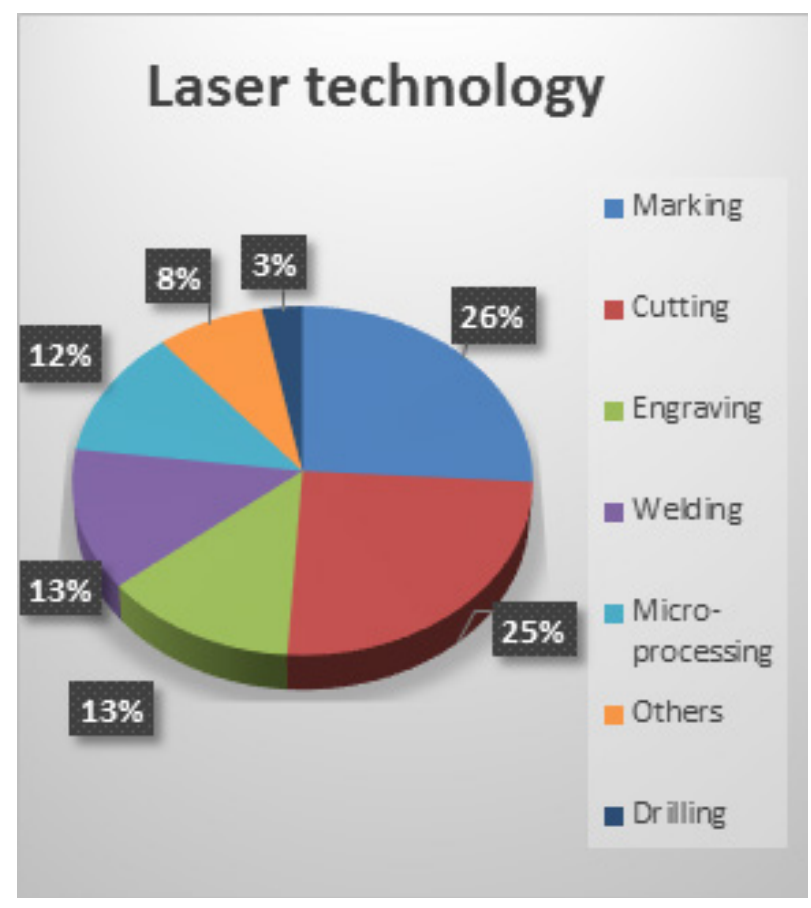

Fig.1. Percentage of Laser used technologies

The area of laser marking and cutting is showed on the figure. A considerable amount of heat is emitted in the marking and cutting processes, so the working area is cooled with air.

The surface power density SPD of the laser beam is determined by:

$$
S P D=\frac{P}{S}
$$

where $\mathrm{P}$ is the power of laser beam and $\mathrm{S}$ is the area of the laser beam section in focus. Laser control was performed using the RdWorks software [8, 14].

There are many methods of part or product marking, including labels, ink systems, mechanical engraving and embossing, chemical and dry etching. Each has its use, but laser marking is growing more and more popular. The utilization of laser engraving of metals is shown in the Fig. 1 where we can compare it with other marking systems in the part production.

\section{LASER MARKING}

The common advantages of all laser marking techniques are [1]:

- $\quad$ permanent, high quality marks;

- $\quad$ high efficiency and low operation cost;

- $\quad$ good accessibility, even to irregular surface;

- non-contact marking and no special working environmental needed;

- $\quad$ easy to automate and integrate (using computercontrolled movement of the beam or sample);

- $\quad$ precise beam positioning and a beam highly localised energy transfer to the workpiece [6];

- $\quad$ high reproducibility and high speed;

- contamination - free.

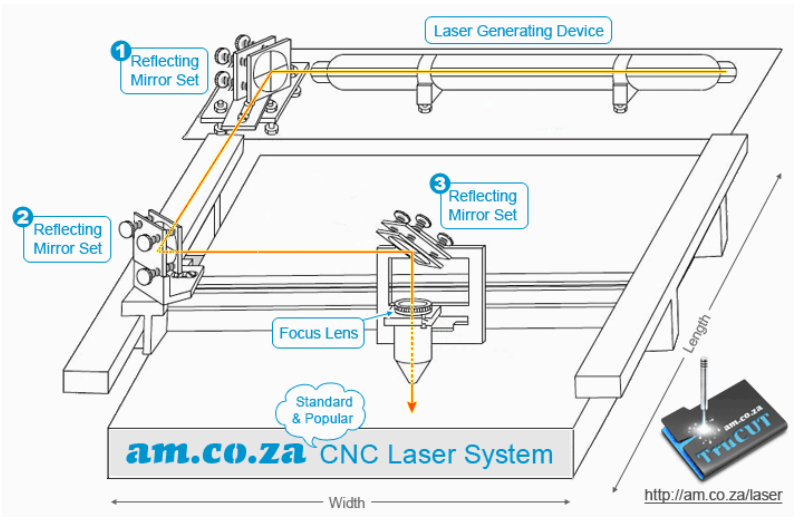

Fig.2 Laser system

Fig.2. shows the scheme of the laser that we use for the experiment and on it we are able to see the different part of $\mathrm{CO}_{2}$ laser, including Laser Generating Device, $3 x$ Reflecting Mirror Set and Focus Lens $[11,12]$.

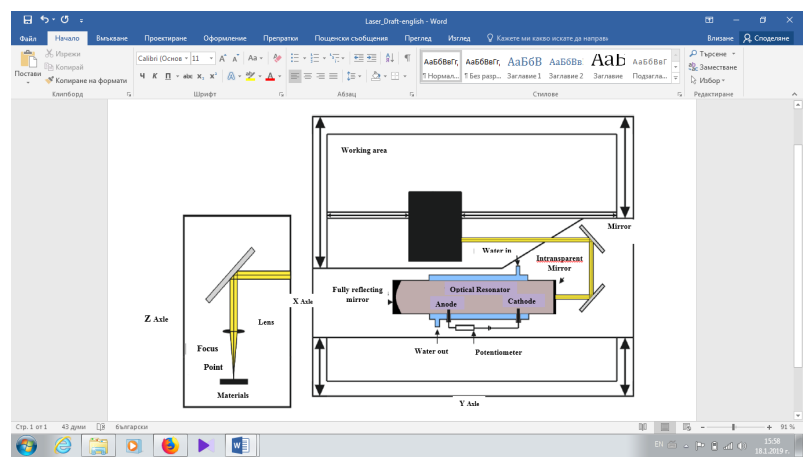

Fig.3. Schematic diagram of $\mathrm{CO}_{2}$ laser

Fig. 3 shows more precisely the schematic diagram of $\mathrm{CO}_{2}$ laser. It includes also the working area, fully reflecting mirror, intransperant mirror, then anodes and cathodes, the lens and the focus point $[2,9,16]$.

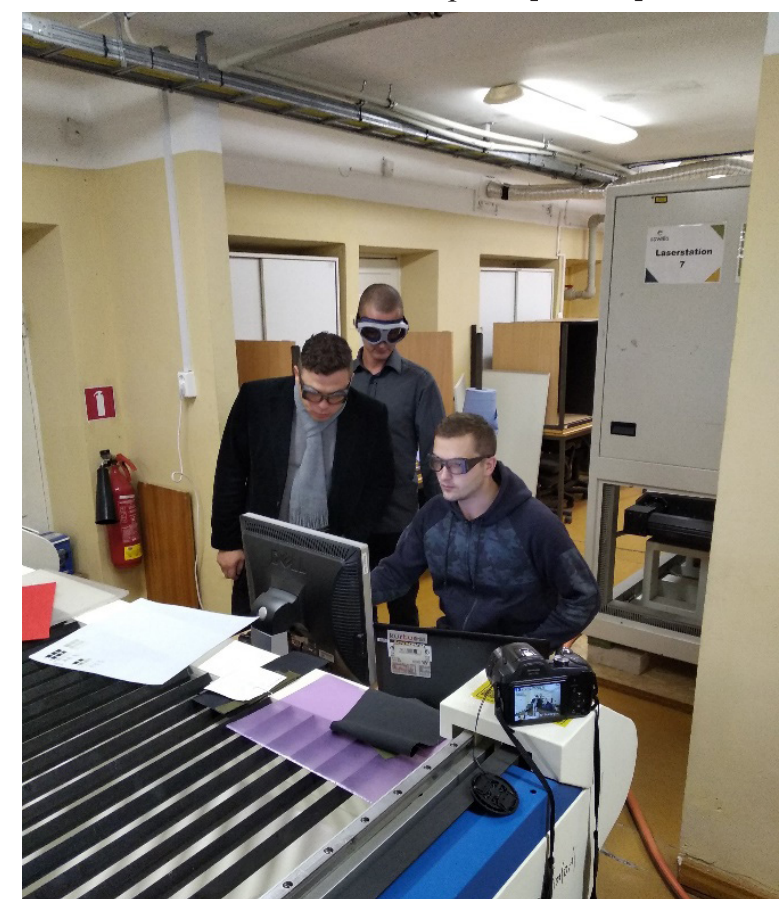

Fig.4. The laser used for the experiments 
Fig. 4 This figure is an image of the laser used during our experiment. It is located in the laser center of the Technological Academy in Rezekne and under it under the supervision of Professor Lubomir Lazov the markings on the research field were carried out.

The abbreviation LASER comes from Light Amplification by Stimulated Emission of Radiation. The quality of a mark is assessed by its legibility characteristics such as mark contrast, mark width, mark depth, and microstructures. The characteristics are usually evaluated using complementary techniques such as optical microscopy, ultrosonics microscopy, electron microscopy, surface roughness measurement. In beam deflected marking, the line width is mainly determined by the focused beam spot size, which varies between $20-100 \mu \mathrm{m}$. Other parameters: scanning speed, power density and material properties also affect the line width. [1].

In relation to the influence of the laser beam on the fabric, the linear energy density LED of the laser beam is defined on a unit length depending on the velocity:

$$
L E D=\frac{P}{v}
$$

where $\mathrm{P}$ is the power of laser beam and $v$ is the speed of laser beam movement on the felt $[2,7]$.

TABLE 1. LED PARAMETERS

\begin{tabular}{|c|l|c|c|c|}
\hline № & $\mathbf{V}$, & $\mathbf{P}=\mathbf{2 W}$ & $\mathbf{P}=\mathbf{1 0 W}$ & $\mathbf{P}=\mathbf{2 6 W}$ \\
\cline { 3 - 5 } & $\mathbf{m m} / \mathbf{s}$ & $\begin{array}{c}\text { LED, } \\
\mathbf{J} / \mathbf{m m}\end{array}$ & $\begin{array}{c}\text { LED, } \\
\mathbf{J} / \mathbf{m m}\end{array}$ & $\begin{array}{c}\text { LED, } \\
\mathbf{J} / \mathbf{m m}\end{array}$ \\
\hline $\mathbf{1}$ & 100 & 0,02000 & 0,10000 & 0,26000 \\
\hline $\mathbf{2}$ & 150 & 0,01333 & 0,06667 & 0,17333 \\
\hline $\mathbf{3}$ & 200 & 0,01000 & 0,05000 & 0,13000 \\
\hline $\mathbf{4}$ & 250 & 0,00800 & 0,04000 & 0,10400 \\
\hline $\mathbf{5}$ & 300 & 0,00667 & 0,03333 & 0,08667 \\
\hline $\mathbf{6}$ & 350 & 0,00571 & 0,02857 & 0,07429 \\
\hline
\end{tabular}

In Table 1 is shown the linear energy density dependences of power $\mathrm{P}$ for $2 \mathrm{~W}, 10 \mathrm{~W}$ and $26 \mathrm{~W}$ and the variation of the speed 100, 150, 200, 250, 300 and 350 $\mathrm{mm} / \mathrm{s}[2]$.

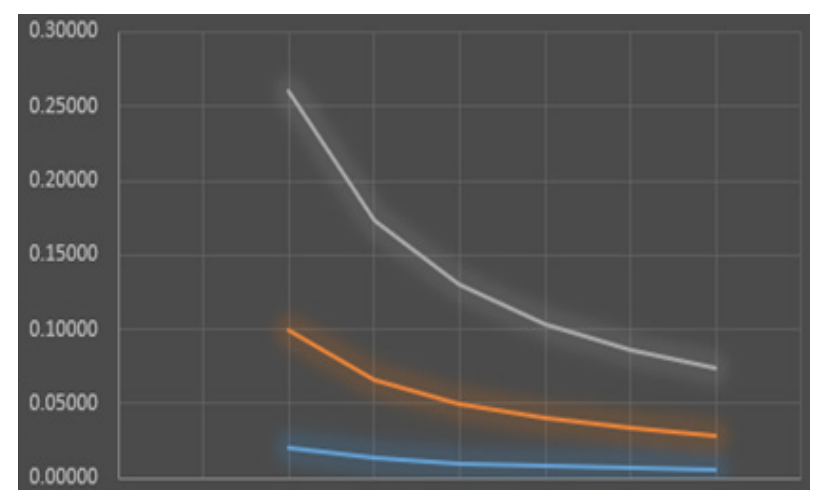

Fig 5. Graphic of changing of LED

In Fig.5 the graphic shows the changing of LED parameters as a result of the interaction between the speed and power.

Each processing area (each square) is implemented with the raster scan method. The line-to-line step is $0.1 \mathrm{~mm}$. The processing areas and the processing quality were analyzed by means of a AM4515ZTL digital microscope manufactured by DINO-LITE:

https://www.dino-lite.eu/index.php/en/products / microscopes/long-working-distance with 1.3 MPx resolution, 10-140X zoom and polarizer.

The diagrams of the square matrices after experiments are shown on Fig 6. The Markings 7, 8, 9 in Figure show respectively the energy of $2 \mathrm{~W}, 10 \mathrm{~W}, 26 \mathrm{~W}$ in percent, which is used for the interaction with a felt.

\section{LASER CUTTING}

- The possibility of laser cutting on a $\mathrm{CO}_{2}$ laser is investigated. For this purpose, an experimental methodology has been developed which consists of the following:

- The processing areas and the processing quality with the help the microscope have been analyzed. Altogether, 90 processing areas were investigated. From the experiments made, the following conclusions can be drawn:

- a quality cut of the material is obtained with the following parameters: for white and red felt - a constant power of $26 \mathrm{~W}(9 \%)$ and a speed ranging 100, 150 and $200 \mathrm{~mm} / \mathrm{s}$ and the LEDs are $0.26 \mathrm{~J} / \mathrm{mm}, 0.17 \mathrm{~J} / \mathrm{mm} 0.13$ $\mathrm{J} / \mathrm{mm}$ - Fig. 4. Quality cutting of the felt.;

- $\quad$ about the same power $26 \mathrm{~W}$ and a speed ranging 250, 300 and $350 \mathrm{~mm} / \mathrm{s}$ and LEDs are $0.104 \mathrm{~J} / \mathrm{mm}$, $0.08667 \mathrm{~J} / \mathrm{mm} 0.0749 \mathrm{~J} / \mathrm{mm}$ the cutting is not full;

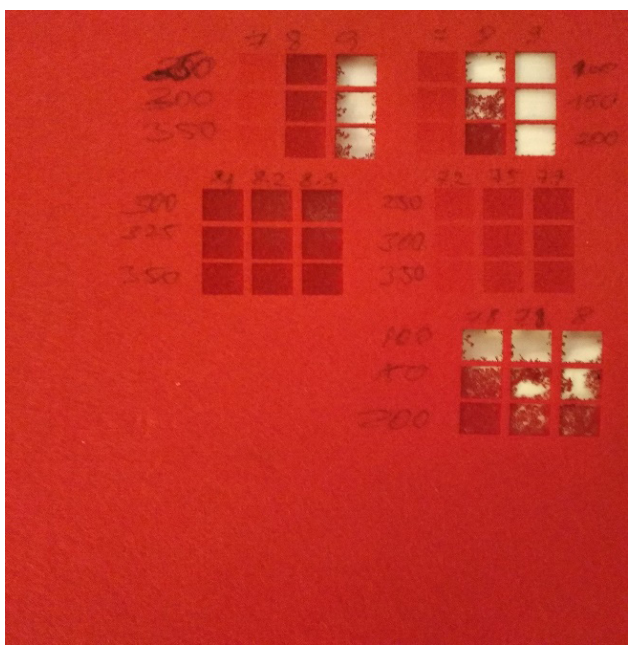

Fig.6. The diagrams of the square matrices

- good marking by lightening of the material (nearly $50 \%$ ) is obtained with the following process parameters: $\mathrm{P}=2 \mathrm{~W}$ and $\mathrm{V}=250,300$ and $300 \mathrm{~mm} / \mathrm{s}$, and the LEDs are $0.008,0.00667$ and 0.00571 as shown in the table 1 - Fig. 8. Red and white felt. Contrast measurements are performed using the Color Contrast Analyzer version: 2.5.0.0. [14];

- $\quad$ about the same power $2 \mathrm{~W}$ and a speed ranging 100,150 and $200 \mathrm{~mm} / \mathrm{s}$ and the LEDs are $0.20 \mathrm{~J} / \mathrm{mm}$, $0.01333 \mathrm{~J} / \mathrm{mm}$ and $0.010 \mathrm{~J} / \mathrm{mm}$ the marking is not so good, it is nearby cutting red and white felt; 


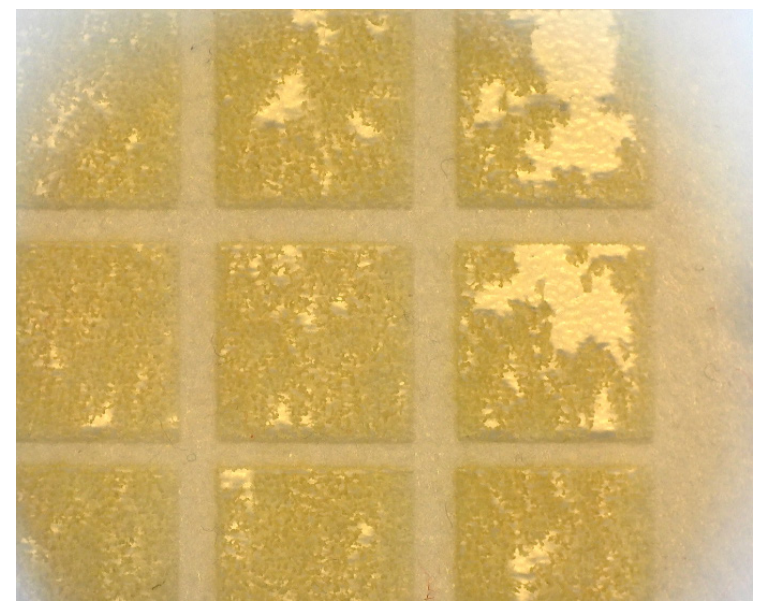

Fig.7. White felt under microscope

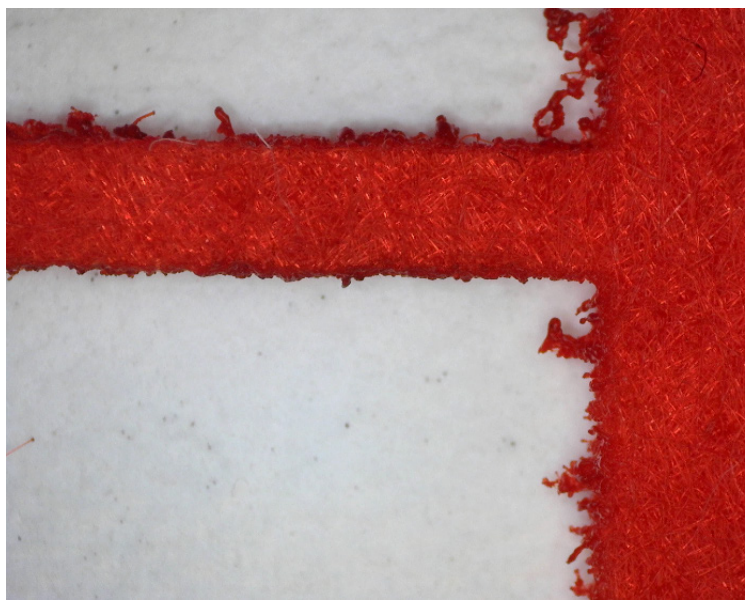

Fig. 8. Cutting of the felt.

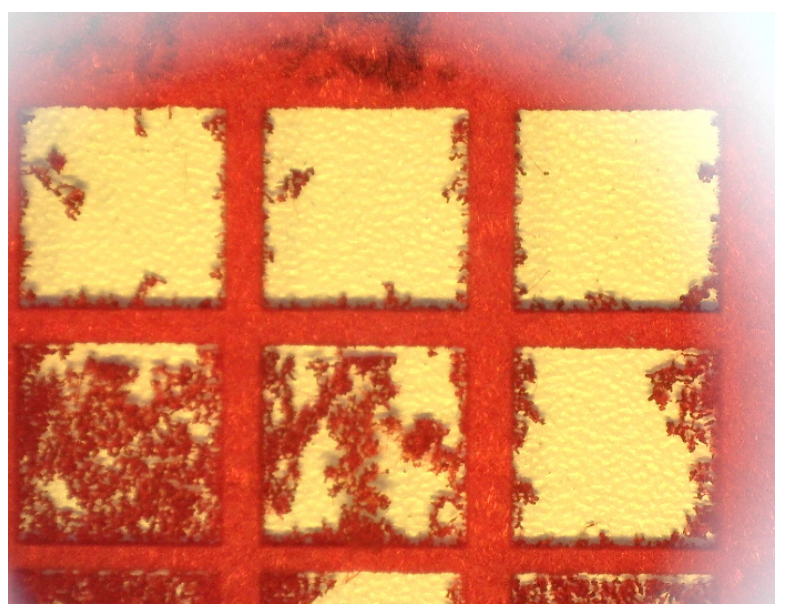

Fig. 9. Cutting of the felt.
- $\quad$ About power $10 \mathrm{~W}$ and speed 100, 150, 200 $\mathrm{mm} / \mathrm{s}$ of laser beam the red felt and white felt have less partial cutting (less destroying felt) and the LEDs are 0.1, $0.06667,0.0 .50$;

- $\quad$ About power $10 \mathrm{~W}$ and speed 250, 300 and 350 $\mathrm{mm} / \mathrm{s}$ of laser beam the red felt and white felt have less partial cutting (less destroying felt) and the LEDs are 0.04, 0.03333, 0.02857;

- $\quad$ About the next areas from all 90 processing areas can say the same analogy.

\section{CONCLUSION}

For all felt materials marking, engraving and cutting can be successfully applied. The choice of laser process is determined by the desired final result.

In this research, the laser applications for and felt processing are analyzed. The advantages of laser technology in felt fields were pointed. The linear energy density during marking and cutting by the laser beam was introduce.

With the help of a robotic automated line, the making of marking and cutting of felt results in the production of an obtained, attractive commercial product [2].

The results in the end of the research are:

1. During the laser cutting on the white felt one of the best parameters of cutting are made in the power of $9 \mathrm{~W}$ and speed of $100 \mathrm{~mm} / \mathrm{s}$ where the cutting is precise. With the increasing of the speed to 150 and $200 \mathrm{~mm} / \mathrm{s}$ the cutting line becomes better, without any mustaches. Unfortunately, this will bring waste of energy.

2. As for the red felt best results in laser cutting are between $100-150 \mathrm{~mm} / \mathrm{s}$ and power of $9 \mathrm{~W}$, but for the speed of $200 \mathrm{~mm} / \mathrm{s}$ and the same power, we are able to see some mustaches left.

3. When we use less power of laser beam there is imperfect cutting. Then we observe laser marking, but not cutting, which depends on the power used for the experiment.

4. The researching felt material is not suitable for laser marking because of its structure is not appropriate for quality work. It is good for laser cutting with low power and the quality is perfect.

5. The results from this experiment can be used as a base for future projects with similar materials and the data base can be practically used during working with $\mathrm{CO}_{2}$ laser. 


\section{REFERENCES}

[1] Dave Ahearn, ONR Laser Power Jumps 10 Fold; Further 10 - Fold Leaps Seen, Defense Today, August 4, 2004, p. 4

[2] Dolchinkov N., Shterev Y., St. Lilianova, D. Boganova, M. Peneva, L. Linkov, D. Nedialkov, Exploring the possibility of laser cutting with $\mathrm{CO}_{2}$ laser on felt in the range from $1 \mathrm{~W}$ to $26 \mathrm{~W}$ power, International scientific journal: Industry 4.0 Issue $1 / 2019$, ISBN 2534-8582, стр. 29-31.

[3] Lamberson S. E., The airborne laser, Proc. SPIE, Gas Chem. Lasers, vol. 2702, pp. 2702-1_2 702 - 6, Mar. 1996

[4] .Lazov L., E. Teirumnieks, Application of laser technology in the army, Proceedings of International Scientific Conference "Defense Technologies", Faculty of Artillery, Air Defense and Communication and Information Systems, Shumen, Bulgaria, 2018

[5] Lazov L, H. Deneva, E. Teirumnieka, Influence of Defocus Position on Laser Cutting Process in Sheet Steel, Environment Technology. Resources, Rezekne, Latvia Proceedings of the 11 th International Scientific and Practical Conference. Volume III, 163-167,

[6] Lazov, L., H. Deneva. Investigation on the Influence of the Process Parameters Power and Velocity to Laser Cutting of Lamellae. Journal of the Technical University - Sofia, Plovdiv branch, Bulgaria, Fundamental Sciences and Applications, Vol. 21, Book 2, 2015, ISSN 1310-8271.
[7] Lazov L., Angelov N., Scanning the contrast in function of velocity in laser marking of samples of steel, International Scientific Conference, Gabrovo, 2010.

[8] Petrov N., Optimization of the marking process with laser radiation of samples of tool steel, dissertation, Gabrovo, 2011.

[9] Shterev Y., N. Dolchinkov, St. Lilianova, D. Boganova, M. Peneva, L. Linkov, D. Nedialkov, Examining the possibility Of marking and engraving of textiel using $\mathrm{CO}_{2}$ laser, International journal for science Machines, Technologies, Materials 12/2018 стр 491-493

[10] https://www.laserfelt.com/

[11] http://chris-reilly.org/blog/how-to-laser-cut-felt/

[12] https://www.epiloglaser.com/resources/sample-club/felt-placemat-cutting.htm

[13] https://www.lasercuttingshapes.com/felt/

[14] https://www.pinterest.com/eleeneelab/laser-cut-felt/

[15] http://digitalcommons.unl.edu/tsaconf/index.2.html

[16] https://developer.paciellogroup.com/resources/contrastanalyser

[17] https://rdworks.software.informer.com

*Note: This article is presented with the assistance of project BG05M2OP001-2.009-0001, Support for the development of human resources and the research potential of the National Military University "Vasil Levski" for its assertion as a modern knowledge center. 